www.jmscr.igmpublication.org Impact Factor 5.244

Index Copernicus Value: 5.88 ISSN (e)-2347-176x ISSN (p) 2455-0450 crossref DOI:_http://dx.doi.org/10.18535/jmscr/v4i6.62

\title{
Extra- Renal Rhabdoid Tumour - Role play of Immunohistochemistry: A Tumour Hiding Behind Veil $\underline{\text { (Case Report) }}$ \\ Authors
}

\section{Dr Priyanka Agnihotri ${ }^{1}$, Dr Shweta Choudhary ${ }^{2}$, Dr Jayanti Mehta ${ }^{3}$, Dr Ajay Yadav ${ }^{4}$, Dr Alka Mittal ${ }^{5}$}

${ }^{1}$ Resident, ${ }^{2}$ Resident, ${ }^{3}$ Professor, ${ }^{4}$ Professor \& Head of Department, ${ }^{5}$ Senior Demonstrator

Department of Pathology, S.M.S. Medical College ,Jaipur, Rajasthan ,India

Corresponding Author

Dr Priyanka Agnihotri

SMS Medical College Girls`Hostel, S.M.S.Medical College, Jaipur, Rajasthan India

Email-privjya@gmail.com

\begin{abstract}
Malignant rhabdoid tumour of soft tissues is a neoplasm of infants \& children having aggressive behavior and poor prognosis. Location of these tumors exhibit wide variety with imaging studies of not much help. Histopathologically these tumour cells exhibit rhabdoid features, as an entity or phenotype still difficult to say. Immunohistochemistry and genetic studies contribute towards excluding other underlying line of differentiation presenting as a close differential and providing confirmatory evidence.

Keywords: Immunohistochemistry, Malignant, Rhabdoid, Soft tissue.
\end{abstract}

\section{INTRODUCTION}

After the first description outside the kidney, socalled rhabdoid tumors have been described at almost every conceivable location, and, although the majority of cases occur in early childhood, the overall age range has been reported to be wide ${ }^{[1]}$. Most evidence suggests that rhabdoid tumor of soft tissues is not a specific tumor entity but rather the expression of a particular phenotype that can develop in a wide variety of tumor types, including epithelioid sarcoma, synovial sarcoma, intra-abdominal desmoplastic small cell tumor, rhabdomyosarcoma, malignant melanoma, and various types of carcinoma. Of practical importance is the fact that the emergence of the rhabdoid phenotype is invariably associated with an aggressive and often lethal clinical course ${ }^{[2]}$.

\section{CASE REPORT}

A 16 year old young woman presented with left gluteal swelling since 8 months for which she was operated. Histopathological specimen received showed an irregular nodular soft tissue mass measuring $7 \mathrm{x} 5 \mathrm{x} \quad 4 \mathrm{~cm}$.On cutting mass was partially capsulated . Cut surface was grey brown to grey tan, heterogenous with multiple tiny cystic areas .Sections were cut from blocks and slides prepared were stained with Haematoxylin \& Eosin for routine histomorphological study and various Immunohistochemistry stains were applied to reach the final diagnosis.

Microscopically, biopsy comprised of sheets and trabeculae of pleomorphic neoplastic cells with round to oval, eccentric to central nuclei with dense eosinophilic cytoplasm [Figure 1 ] and a 
diagnosis of Malignant round cell tumour with possibility of alveolar rhabdomyosarcoma was rendered. Rest of sections were processed for immunhistochemistry for further confirmation .

On performing immunohistochemistry, neoplastic cells were Positive for CD 99,Vimentin, Epithelial membrane antigen and Pan-Cytokeratin [Figure 2 \& 3 ]. Cells were Negative for CD34,Desmin, Myogenin and S-100.There was also loss of INI-1 expression[Figure 4]. Mib -LI Score was $10 \%$. Thus overall study favored final diagnosis of Extra- Renal Rhabdoid Tumour (Malignant).

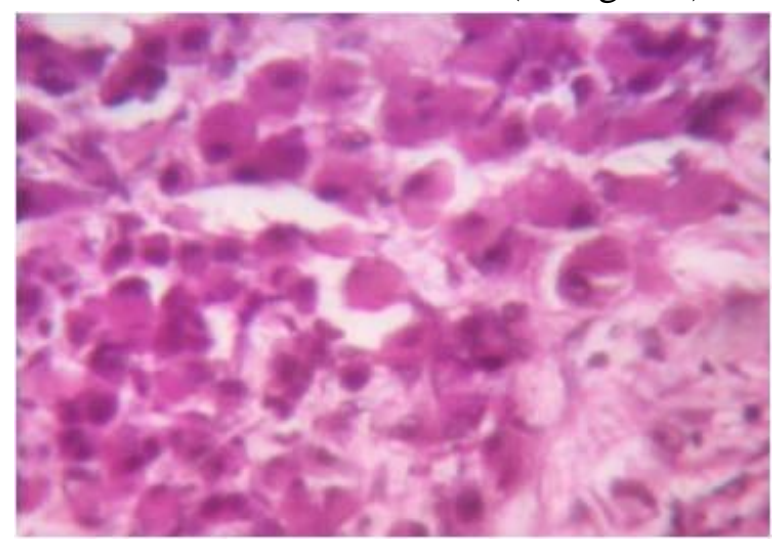

Figure 1 - Sheets of neoplastic cells showing rhabdoid features

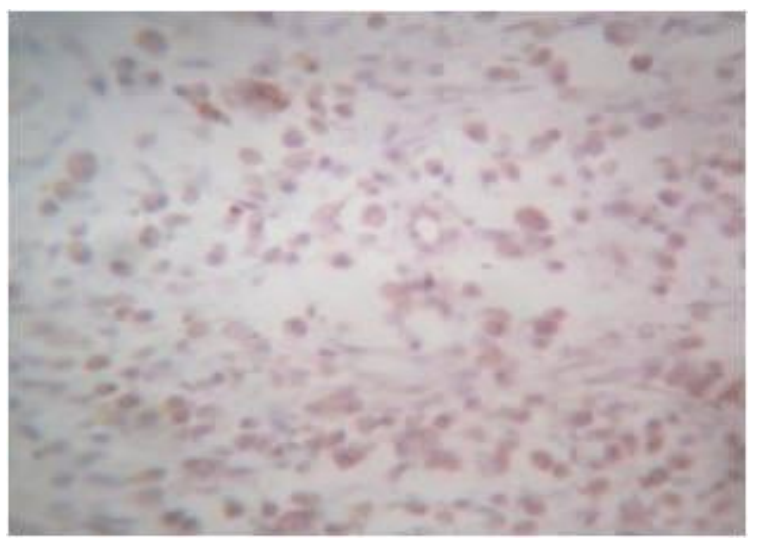

Figure 2 - Cells are immunoreactive for Pan Cytokeratin

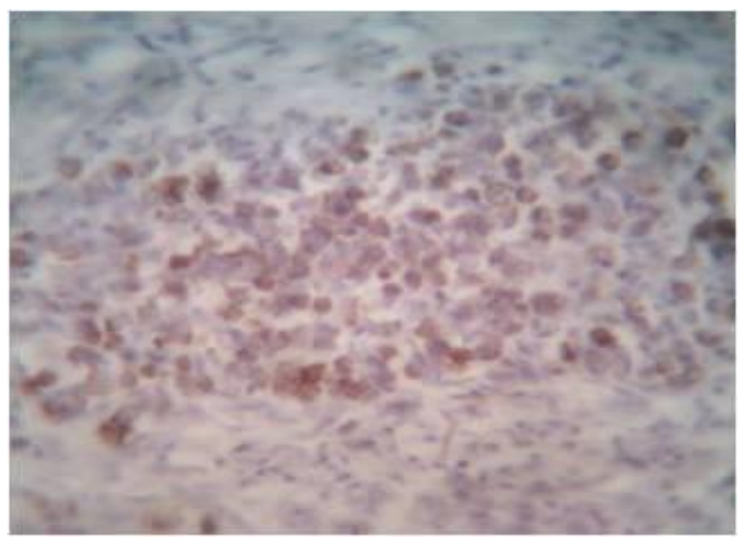

Figure 3 - Neoplastic cells show positivety for Epithelial membrane antigen

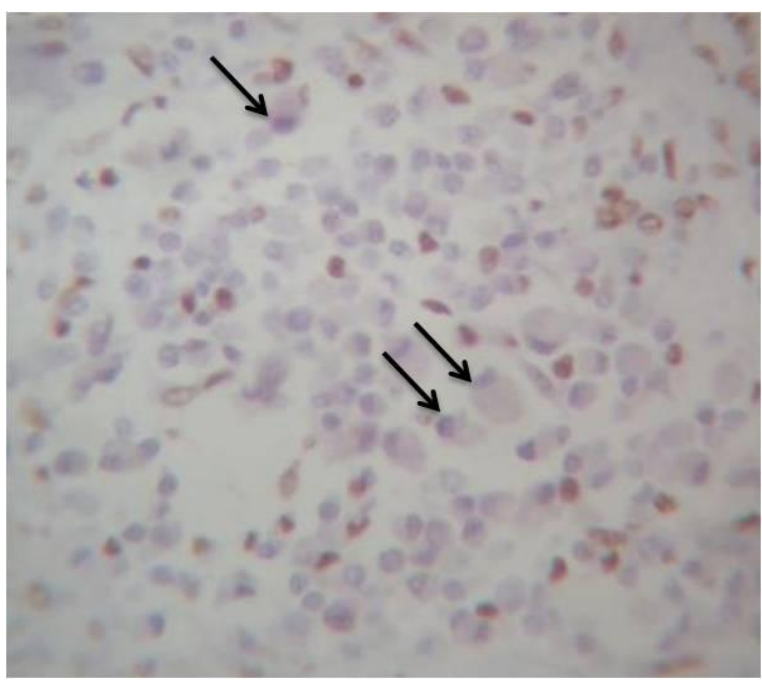

Figure 4- Malignant rhabdoid cells showing loss of INI-1 expression on immunohistochemistry

\section{DISCUSSION}

Soft tissue rhabdoid tumour is a malignant tumour of infants and children, characterized by neoplastic cells with large nuclei, prominent nucleoli, and abundant, eccentric cytoplasm with variably prominent eosinophilic, cytoplasmic "inclusions". These inclusions are ultra structurally composed of whorls of intermediate filaments. Since a rhabdoid phenotype may be present in a wide spectrum of tumours, particularly those occurring in adults, the diagnosis of rhabdoid tumour requires exclusion of an underlying alternative line of differentiation [3].

The imaging characteristics of soft-tissue rhabdoid tumors have yet to be determined, largely because of the rarity of these tumors. Recently, GarcésIñigo et al. described the largest case series in the radiology literature; no specific imaging features were observed that could prove diagnostic for these tumors, however, Garcés-Iñigo et al. did show that these tumors have a tendency to be large and hypodense on CT, and show a heterogeneous hyperintensity on T2-weighted (W) magnetic resonance (MR) imaging. To our knowledge, only a few cases of hepatic and none of malignant uterine rhabdoid tumors have been described in the radiology literature previously ${ }^{[4]}$. Microscopically, the tumor is composed of a diffuse proliferation of rounded or polygonal cells with eccentric nuclei, prominent nucleoli and 
glassy eosinophilic cytoplasm containing hyalinelike inclusion bodies, arranged in sheets and nests. These characteristic 'rhabdoid cells' are also present in certain soft-tissue sarcomas such as synovial sarcoma, extraskeletal myxoid chondrosarcoma and leiomyosarcoma. The existence of rhabdoid cells in these other sarcomas is correlated with a worse prognosis for the patients. Cytogenetic and molecular analyses have shown abnormalities in the long arm of chromosome 22 and alteration of the hSNF5/INI1 (SMARCB1) gene in renal, extrarenal and intracranial malignant rhabdoid tumour. This gene alteration has been considered to be a specific molecular event in malignant rhabdoid tumour, but a recent study has also demonstrated frequent alteration of this gene in proximal-type epithelioid sarcoma (ES). Both malignant rhabdoid tumour of soft tissue and proximal-type epitheloid sarcoma show immunoreactivity for vimentin, cytokeratin and epithelial membrane antigen. The tumor cells of proximal-type ES are also occasionally positive for CD34 and beta-catenin, whereas malignant rhabdoid tumour of soft tissue has no immunoreaction for these markers ${ }^{[5]}$.

In our case neoplastic cells had histomorphology of rhabdoid cells arranged in sheets with expression of Vimentin, Epithelial membrane antigen and Pan-Cytokeratin but negative for CD 34 thus favouring malignant rhabdoid tumour over epitheloid sarcoma. Microscopic findings along with negativety for S-100, Desmin \& Myogenin ruled out other differentials such as rhabdomyosarcoma, epitheloid sarcoma, desmoplastic round cell tumour etc.

Furthur clue to diagnosis heralded from demonstration of loss of INI-1 expression on immunohistochemistry.

\section{CONCLUSION}

Extra- renal malignant rhabdoid tumour, a tumour of predominantly young age group may mimic many other tumours clinically as well as histopathologically. Collaboration of clinical and pathological findings along with immunohisto- chemistry may help in providing clue towards diagnosis of this aggressive 'tumour hiding behind veil'. For exact confirmation molecular detection methods may be used .However prognosis of these patients still remain dismal.

\section{ACKNOWLEDGEMENTS}

We gratefully acknowledge the support of our technical staff for their helpful and skillfull assistance.

\section{DECLARATIONS \\ Funding: None \\ Conflict of interest: None declared}

\section{REFERENCES}

1. Christopher D.M. Fletcher. Tumours of Soft Tissue.In: Diagnostic Histopathology of tumours .4th ed. Philadelphia, PA.2013,pp. 1853

2. Juan Rosai .Soft Tissues .Vol.2.In.Rosai and Ackerman`s Surgical Pathology .10th ed. St.Louis.Missouri.2011.pp2189

3. D. Schofield.Extrarenal rhabdoid tumour In.W.H.O.classification of tumours of soft tissue and bone.IARC Press. Lyon, France.2002,pp.219

4. Asif Abdullah, Yogesh Patel, Terrence J. Lewis, Haitham Elsamaloty, and Stephen Strobel. Extrarenal malignant rhabdoid tumors: radiologic findings with histopathologic correlation. Cancer Imaging. 2010; 10(1): 97-101

5. Oda Y, Tsuneyoshi M. Extrarenal rhabdoid tumors of soft tissue: Clinicopathological and molecular genetic review and distinction from other softtissue sarcomas with rhabdoid features. Pathol Int. 2006 Jun;56(6):287-95. 